\title{
CHEMICAL EVIDENCE IN POLAR ICE CORES FROM DIELECTRIC PROFILING
}

\author{
by \\ J.C. Moore, \\ (Institute of Low Temperature Science, Hokkaido University, Sapporo 060, Japan) \\ J.G. Paren and R. Mulvaney \\ (British Antarctic Survey, Natural Environment Research Council, High Cross, \\ Madingley Road, Cambridge CB3 0ET, England. U.K.)
}

\section{ABSTRACT}

The dielectric stratigraphy of a $130 \mathrm{~m}$ ice core from Dolleman Island, Antarctic Peninsula, shows large variations in the dielectric relaxation process and in conductivity. A comparison with the chemical stratigraphy of the core demonstrates the decisive role played by both acids and salts in determining the electrical behaviour of natural ice. The dielectric response is sensitive both to the type of impurity and to its distribution within the ice fabric. The evidence supports other observations of the localization of sulphuric acid at three-grain boundaries: in contrast, the salt impurity appears to be largely incorporated into the ice lattice. The overriding importance of the dielectric profiling technique is that it is the only profiling tool so far developed that is sensitive to the presence of salt in polar ice cores.

\section{INTRODUCTION}

Trace levels of impurity have been shown to affect the dielectric behaviour of ice grown from dilute solutions in the laboratory (Camplin and others, 1978; Gross and others, 1978; Takei and Maeno, 1987). No similar study has been made on the ice of polar ice sheets. Dielectric measurements (Paren, 1973; Fitzgerald and Paren, 1975; Glen and Paren, 1975), undertaken at the time that the technique of radar sounding (RES) ice sheets at HF-VHF was being developed, showed a general uniformity of behaviour, so that, for RES purposes, polar ice had a simple well defined temperaturedependent response (Fitzgerald and others, 1977). The discovery during RES flights of internal reflections from deep within the ice sheets (Robin and others, 1969; Harrison, 1973; Gudmandsen, 1975) implied there to be a source of variability in the ice. The most likely source of this variability is from changes in the dielectric conductivity of ice (Paren and Robin, 1975; Millar, 1981). Reynolds (1985) showed there were marked dielectric differences between the ice recovered from the cold interiors of polar regions and the ice of the warmer coastal areas. A chemical explanation of these differences was possible: there is a large increase in concentrations of impurities at coasts compared with more continental areas (Heron, 1982; Legrand, 1987). Dramatic changes in ice chemistry are usually associated with large discrete events such as volcanic eruptions (Hammer, 1980, Maccagnan and others, 1981) or changes in climate between ice ages and interglacials (Legrand and others, 1988).

To date the only physical technique sensitive to the chemical composition of the solid ice is the rapid stratigraphic analysis of ice cores by the electrical conductivity measurement (ECM) method developed by Hammer (1980). This powerful technique has identified acidic deposition following volcanic eruptions, and also annual cycles of acidity in Greenland precipitation. The technique requires a freshly cut ice surface over which two electrodes $\left(i .5 \mathrm{~mm}^{2}\right)$ a few cm apart are drawn with a potential of about $1 \mathrm{kV}$ between them. The current flowing between the electrodes is sensitive to the acid content and the thermal history of the ice (Hammer, 1980; Maccagnan and others, 1981), but is independent of the salt concentration (Hammer, 1980). For repeatable current measurements a new surface must be prepared.

\section{DIELECTRIC PROFILING (DEP) TECHNIQUE}

The DEP technique (Moore and Paren, 1987) has one major advantage over ECM profiling; it is that no direct contact needs to be made between ice and electrodes, so that the core remains in good condition for any further analysis. In addition, the method is non-destructive and gives repeatable results with an exciting voltage of only $1 \mathrm{~V}$.

The Dolleman Island core was measured with a resolution of $5 \mathrm{~cm}$ down its $130 \mathrm{~m}$ length. Dielectric parameters are measured at 42 frequencies between $20 \mathrm{~Hz}$ and $300 \mathrm{kHz}$. A $1 \mathrm{~m}$ length of core can be measured in 20 minutes. The ice within a protective polythene sleeve behaves as an electrical blocking layer system. Formulae are available (Gross and others, 1980) for extracting the intrinsic ice behaviour from that of the composite blocking system, but a critical parameter, the size of the variable gap between the electrode and the ice, is not accurately known. We find it satisfactory to use the dielectric parameters of the composite system alone to relate to the chemical stratigraphy. At LF $(\sim 100 \mathrm{kHz})$, the conductivity of the composite system is within a few per cent of that intrinsic to the ice, and approximates well to the conductivity of ice in the RES frequency range. This conductivity, $\sigma_{\infty}$, is at a frequency much higher that the relaxation frequency, $\mathrm{fr}$, of the dominant dielectric dispersion of the blocking layer system. Both $\sigma_{\infty}$ and $\mathrm{fr}$ display a good correlation with chemistry despite noise from the effect of the variable electrode/polythene/ice contact. The effects of the blocking layer mean that fr cannot be directly compared with values for the relaxation frequency of ice. The blocking layer also leads to a higher experimental scatter in the value of $\mathrm{fr}$ than in $\sigma_{\infty}$. We have found that for the Dolleman core $\mathrm{fr}$ is a useful additional parameter to $\sigma_{\infty}$; however, its dependence on factors that are not intrinsic to the ice may mean that $\mathrm{fr}$ has limited value in the dielectric analysis of other cores.

\section{COMPARISON OF DEP AND CHEMICAL DATA}

The only ice core so far studied both dielectrically (Moore, 1988) and chemically is the $130 \mathrm{~m}$ core from Dolleman Island $\left(70^{\circ} 35^{\prime} \mathrm{S}, 60^{\circ} 55^{\prime} \mathrm{W}\right.$; elevation $400 \mathrm{~m}$, mean annual temperature $-17^{\circ} \mathrm{C}$ ). A continuous $45 \mathrm{~m}$ section from between $26 \mathrm{~m}$ and $71 \mathrm{~m}$ depths has been analyzed for $\mathrm{Na}^{+}$, $\mathrm{Mg}^{2+}, \mathrm{Cl}^{-}, \mathrm{SO}_{4}^{2-}, \mathrm{NO}_{3}^{-}$. The anions were measured using a Dionex $2010 \mathrm{i}$ ion chromatography instrument; the instrument has an accuracy of $5 \%$ and a detection limit of about $0.05 \mu \mathrm{M}$. The cations were analyzed by flame atomic 
absorption spectrometry using a Pye Unicam SP9. The precision of the technique is about $3 \%$. The detection limit is about $0.1 \mu \mathrm{M}$ for $\mathrm{Na}$ and about $0.05 \mu \mathrm{M}$ for $\mathrm{Mg}$. The chemical data sets are at a higher resolution than the DEP data set, so the chemical data have been interpolated using a cubic spline function which has then been averaged over the $10 \mathrm{~cm}$ length of core sampled by the DEP electrodes in each measurement. This has provided 807 sets of chemical and dielectric data for comparison. The DEP data were obtained at $-22^{\circ} \mathrm{C}$. All sections of the core have been subject to the same thermal history since drilling. The temporal resolution of the data is equivalent to one month's snowfall.

The average chemical compositon of the core in units of $\mu \mathrm{eq} \mathrm{l}^{-1}$ is $\mathrm{Na}^{+}$: 11.2, $\mathrm{Mg}^{2+}: 2.7, \mathrm{Cl}^{-}: 14.64, \mathrm{SO}_{4}^{2-}: 4.76$, $\mathrm{NO}_{3}^{-}: 0.55$. A statistical analysis of the relationships between chemical and dielectric species shows only scaling chemical and dielectric species show or $\sigma_{\infty}$ on $\mathrm{Na}^{+}$and $\mathrm{Mg}^{2+}$. We have therefore introduced a parameter "salt" (mean value $14.59 \mu \mathrm{eq}^{-1}$ ) given by:

$$
[\text { salt }]=1.05\left(\left[\mathrm{Na}^{+}\right]+\left[\mathrm{Mg}^{2+}\right]\right)
$$

which represents the total marine cation concentration in the ice. The total anion concentration has a mean value of $19.95 \mu \mathrm{eq} 1^{-1}$ and is given by:

$$
\text { [anions }]=\left[\mathrm{Cl}^{-}\right]+\left[\mathrm{SO}_{4}^{2-}\right]+\left[\mathrm{NO}_{3}^{-}\right]
$$

The total concentration of strong acid in the ice (mean value $5.36 \mu \mathrm{eq}^{-1}$ ), made up of contributions from $\mathrm{HCl}$, $\mathrm{H}_{2} \mathrm{SO}_{4}$ and $\mathrm{HNO}_{3}$ is given by:

$$
[\text { acid }]=[\text { anions }]-[\text { salt }]
$$

This method of calculating acid concentrations has been verified by comparison with $\left[\mathrm{H}^{+}\right]$measured directly by acid titration on 63 samples (Fig. 1).
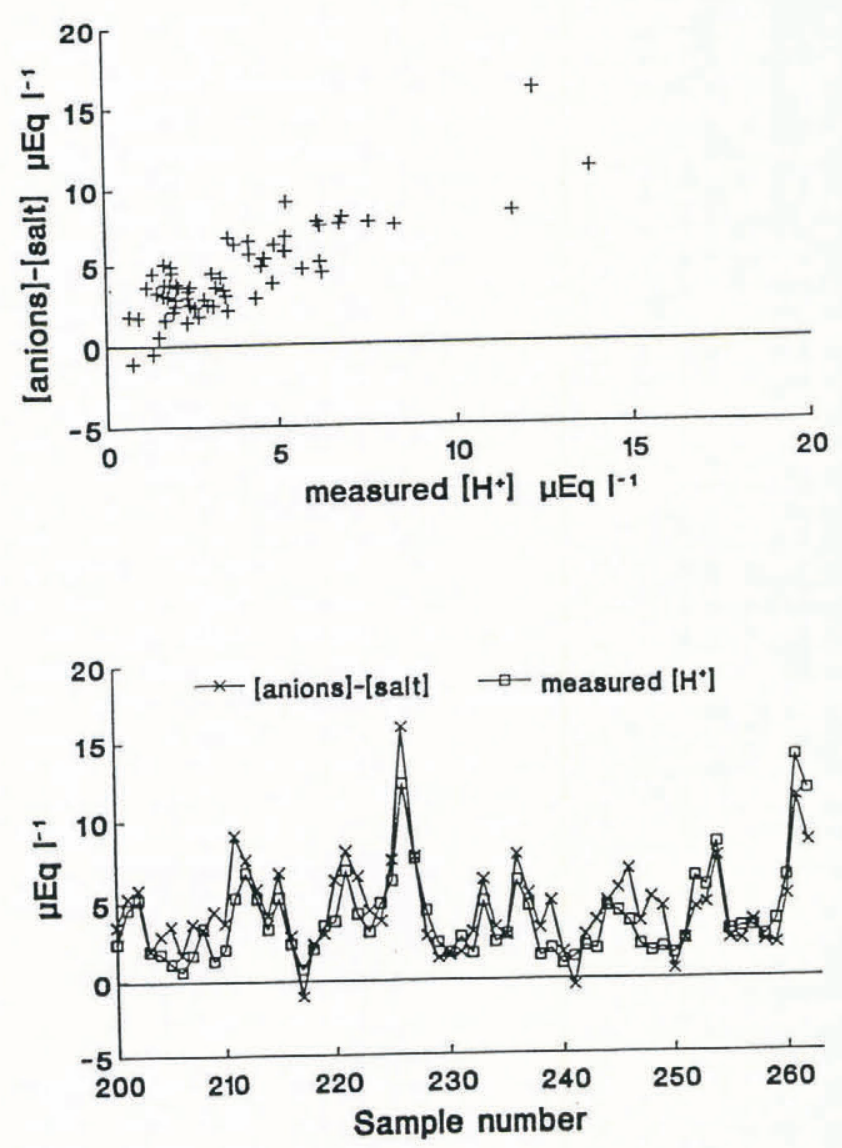

Fig. 1. A comparison of the measured $\left[\mathrm{H}^{+}\right]$found by acid titration and calculated $\left[\mathrm{H}^{+}\right]$found from the difference between total anions and marine cations for 63 samples from the Dolleman core. The anions are averaged over $10 \mathrm{~cm}$ intervals to match the DEP sample width (about 5 samples per year accumulation).
The chemical composition of the Dolleman core is complicated and will be discussed elsewhere. There are localized variations in ionic ratios from those of normal sea water, which makes the calculation of each individual strong acid concentration difficult to determine accurately. However, it is clear than in general $\mathrm{H}_{2} \mathrm{SO}_{4}$ is the dominant acid. Because of the difficulty of separating out the individual acid concentrations, it has not been possible to examine any differences in their effects on the dielectric behaviour. Therefore, the dielectric behaviour has been studied as a function of the "salt" and "acid" parameters. A non-linear regression analysis of the dependence of the dielectric parameters on the chemical parameters yielded functions with linear exponents:

$$
\begin{aligned}
& \sigma_{\infty}=0.39[\text { salt }]+1.43[\text { acid }]+12.7 \\
& \text { s. }_{2} 440[\text { salt }]+612[\text { acid }]+8200
\end{aligned}
$$

The dependence of anions on the dielectric parameters, however, produced a non-linear fit:

$$
\text { [anions] }=0.022 \sigma_{\infty}{ }^{1.89}+1 \times 10^{-6} \mathrm{fr}^{1.61}
$$

The units of $\sigma_{\infty}$ are $\mu \mathrm{S} \mathrm{m}^{-1}$, those of $\mathrm{fr}$ are $\mathrm{Hz}$ and the chemical quantities are $\mu$ eq $1^{-1}$. Relation (4) accounts for $86.7 \%$ of the variance of [anions]. The total anion concentration predicted from Equation (4) can be compared with the measured total anion concentration in Figure 1. It can be seen from Equations (2) and (3) that the salt and acid produce quite different effects on the dielectric parameters, with a given amount of acid producing over three times the change in $\sigma_{\infty}$ produced by the same amount of salt.

Although the dependence of the dielectric parameters on the chemical species can be expressed as simple linear relationships, the inverse relationship for anions is non-linear in the dielectric variables. This probably results from the way in which salt and acid display annual cycles that are out of phase. Thus the dependence of [anions] is probably dependent on the individual ice core chemistry, whilst the $\sigma_{\infty}$ and $\mathrm{fr}$ relations should be applicable to any ice core at the same temperature.

\section{DISCUSSION}

The coefficient of acid in Equation (2) can be compared with that expected from the model of Wolff and Paren (1984). This model is based on the localization of acids at three grain boundaries in the liquid state. Acids then contribute the d.c. term to $\sigma_{\infty}$. Recent work by Mulvaney and others (1988) supports the localization of sulphur (chiefly $\mathrm{H}_{2} \mathrm{SO}_{4}$ ) at triple grain junctions in Dolleman ice. The acid is sufficiently concentrated to remain liquid at temperatures above $-70^{\circ} \mathrm{C}$, forming a network of conducting veins in the ice. The model predicts a linear dependence of $\sigma_{\infty}$ on [acid] with a constant of proportionality dependent on the relative concentrations of each acid. For the Dolleman core the dominant acid is $\mathrm{H}_{2} \mathrm{SO}_{4}$, which at $-22^{\circ} \mathrm{C}$ would give a constant of proportionality of $1.41 . \mathrm{HCl}$ and $\mathrm{HNO}_{3}$ produce higher constants around 2.4 ; we would therefore expect a value close to that observed in Equation (2) of 1.43. The dependence of $\mathrm{fr}$ on [acid] shown in Equation (3) is not easily explainable by the model of Wolff and Paren since no dispersion is predicted for the acid veins in the AF-LF frequency range. The observed dependence of $\mathrm{fr}$ is probably an artifact of the composite blocking layer system, rather an a real variation in intrinsic ice relaxation frequency. However, the effect could be a result of some acid component making a contribution to the dielectric conductivity rather than the d.c. conductivity. The nature of the salt dependence in Equations (2) and (3) can be explained by the generation of a Bjerrum defect by every one or two salt ions present in the ice (Moore, unpublished). This implies that, in contrast to the acid impurity, a large fraction of the salt impurity is incorporated into the ice lattice.

The $\sigma_{\infty} /$ acid relationship observed for Dolleman ice can be compared with the relationship given by Hammer (1980) 


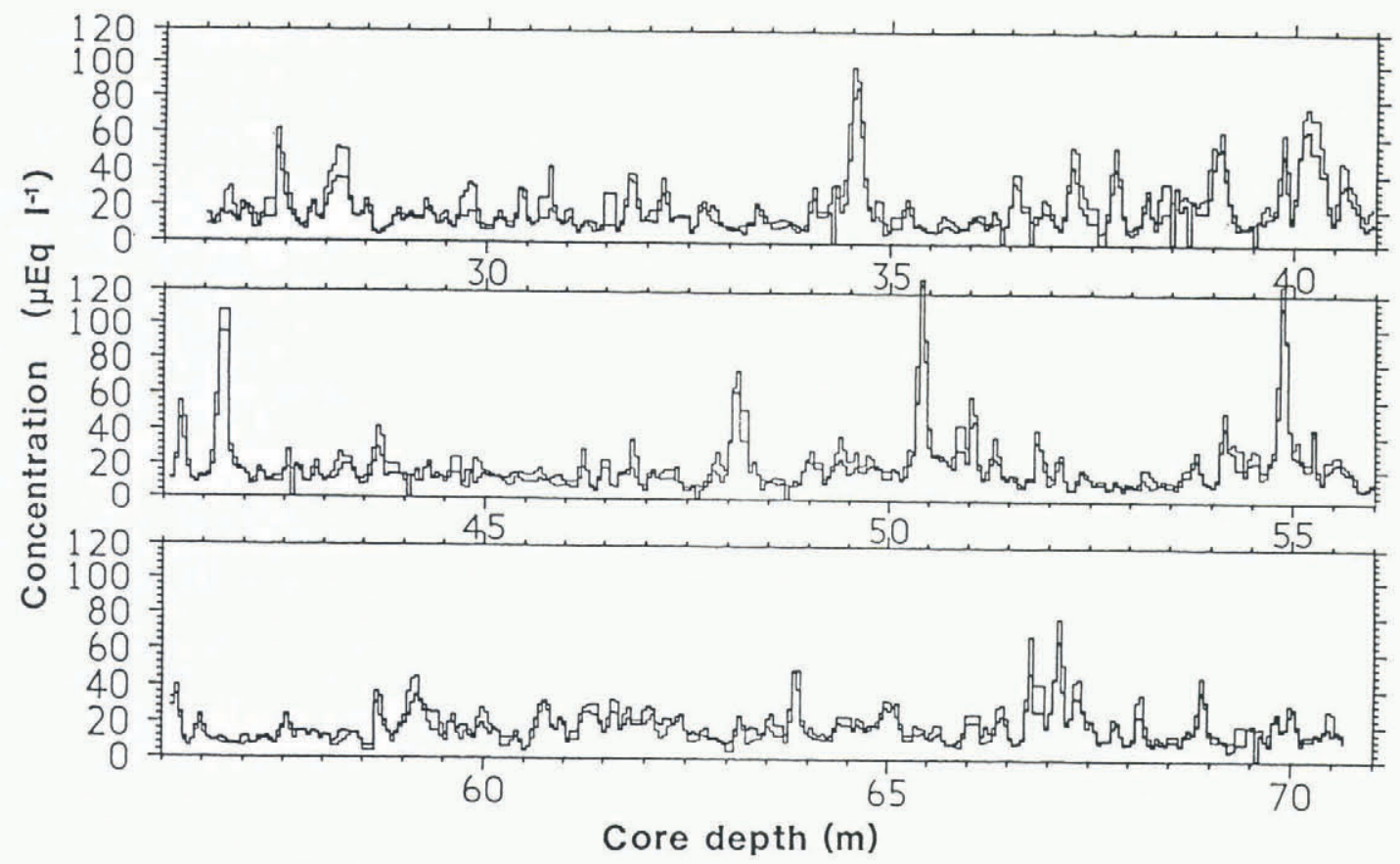

Fig. 2. A comparison of the measured total anion $\left(\mathrm{Cl}^{-}+\mathrm{SO}_{4}^{2-}+\mathrm{NO}_{3}^{-}\right)$concentrations (thin line) and that predicted using Equation (4) (thick line) for the Dolleman Island core between 26 and $71 \mathrm{~m}$ depths.

for the dependence of $\left[\mathrm{H}^{+}\right]$on the ECM current, i, for the Greenland ice at $-14^{\circ} \mathrm{C}$ :

$$
\left[\mathrm{H}^{+}\right]=0.045 \mathrm{i}^{1.73}
$$

where the units of $\left[\mathrm{H}^{+}\right]$are $\mu \mathrm{M}$ and $\mathrm{i}$ are $\mu \mathrm{A}$. Legrand and others (1987) found a similar relationship for two Antarctic sites but with exponents of 1.6 and 2.4 , and an activation energy of $0.25 \mathrm{eV}$. Using this activation energy the relationship between $\mathrm{ECM} \mathrm{i}$ and acidity at $-22^{\circ} \mathrm{C}$ is approximately:

$$
\left[\mathrm{H}^{+}\right]=0.084 \mathrm{i}^{1.73}
$$

Schwander and others (1983) found an empirical linear relationship between ECM current and conductivity that depended on the area of the ECM electrodes and the potential applied. For Hammer's electrode geometry this gives $\sigma \sim 0.57 \mathrm{i}$. Thus there appears to be a difference in the functional relationship between acidity and ECM conductivity, and that with DEP conductivity, that has yet to be explained.

The ECM technique has been found to be very useful in the identification of sections of ice cores which contain high levels of acidity, but the technique is insensitive to neutral salt concentrations. DEP is sensitive to both types of impurity but has lower resolution than ECM. An effective method of estimating the neutral salt contribution of a core with similar chemistry to that of Dolleman Island would be to combine Equations (1), (4) and (5) to produce an equation such as:

$$
\text { [salt }]=0.022 \sigma_{\infty}^{1.89}+1 \times 10^{-6} \mathrm{fr}^{1.61}-0.084 \mathrm{i}^{1.73}
$$

assuming the electrical measurements were all made at $-22^{\circ} \mathrm{C}$. We suggest a more universal relationship results from combining Equations (2) and (5), avoiding the anion relationship (Equation (4)), possibly specific to Dolleman Island alone, giving:

$$
[\text { salt }]=\left(\sigma_{\infty}-0.120 \mathrm{i}^{1.73}-12.7\right) / 0.39
$$

Using the latter equation (Equation (7)) it should be possible to rapidly analyze an ice core using only electrical techniques to determine both total acid concentrations and neutral salt concentrations.

\section{ACKNOWLEDGEMENTS}

J.C. Moore wishes to acknowledge the generosity of the Transantarctic Association who provided travel funds for presentation of this paper at the Seattle symposium.

We thank A. Reid, E. Suttie and E. Wolff for some of the chemical analyses.

\section{REFERENCES}

Camplin, G.C., J.W. Glen, and J.G. Paren. 1978. Theoretical models for interpreting the dielectric behaviour of HF-doped ice. J. Glaciol., 21(85), 123-141.

Fitzgerald, W.J. and J.G. Paren. 1975. The dielectric properties of Antarctic ice. J. Glaciol., 15(73), 39-48.

Fitzgerald, W.J., J.G. Paren, and J.W. Glen. 1977. Are the anomalous properties of polar ice due to impurities? IASH Publication 118, 3-8.

Glen, J.W. and J.G. Paren. 1975. The electrical properties of snow and ice. J. Glaciol., 15(73), 15-38.

Gross, G.W., I.C. Hayslip, and R.N. Hoy. 1978. Electrical conductivity and relaxation in ice crystals with known impurity content. J. Glaciol., 21(85), 143-160.

Gross, G.W., I.C. Hayslip, and R.N. Hoy. 1980. Dielectric relaxation spectrum of ice measured with linear blocking layers. Geophysics, 45(5), 914-927.

Gudmandsen, P. 1975. Layer echoes in polar ice sheets. $J$. Glaciol., 15(73), 95-101.

Hammer, C.U. 1980. Acidity of polar ice cores in relation to absolute dating, past volcanism, and radio echoes. $J$. Glaciol., 25(93), 359-372.

Harrison, C.H. 1973. Radio echo sounding of horizontal layers in ice. J. Glaciol., 12(66), 383-397.

Herron, M.M. 1982. Impurity sources of $\mathrm{F}^{-}, \mathrm{Cl}^{-}, \mathrm{NO}_{3}^{-}$and $\mathrm{SO}_{4}{ }^{2-}$ in Greenland and Antarctic precipitation. $J$. Geophys. Res., 87(C4), 3052-3060.

Legrand, M.R. 1987. Chemistry of Antarctic snow and ice. J. Phys. (Paris), 48, Colloq. C1, 77-86. (Supplément au 3.)

Legrand, M.R., J.-R. Petit, and Y.S. Korotkevich. 1987. D.C. conductivity of Antarctic ice in relation to its chemistry. J. Phys. (Paris), 48, Colloq. C1, 605-611. (Supplément au 3.)

Legrand, M.R., C. Lorius, N.I. Barkov, and V.N. Petrov. 1988. Vostok (Antarctica) ice core: atmospheric chemistry changes over the last climatic cycle (160,000 years). Atmos. Environ., 22(2), 317-331. 
Maccagnan, M., J.M. Barnola, R. Delmas, and P. Duval. 1981. Static electrical conductivity as an indicator of the sulphate content of polar ice cores. Geophys. Res. Lett., 8(9), 970-972.

Millar, D.H.M. 1981. Radio-echo layering in polar ice sheets and past volcanic activity. Nature, 292(5822), 441-443.

Moore, J.C. 1988. Dielectric variability of a $130 \mathrm{~m}$ Antarctic ice core: implications for radar sounding. Ann. Glaciol., 11, 95-99.

Moore, J.C. Unpublished. Geophysical aspects of ice core drilling in Antarctica. (Ph.D. thesis, Council for National Academic Awards, 1988.)

Moore, J.C. and J.G. Paren. 1987. A new technique for dielectric logging of Antarctic ice cores. J. Phys. (Paris), 48, Colloq. C1, 155-160. (Supplément au 3.)

Mulvaney, R., E.W. Wolff, and K. Oates. 1988. Sulphuric acid at grain boundaries in Antarctic ice. Nature, 331(6153), 247-249.

Paren, J.G. 1973. The electrical behavior of polar glaciers. In Whalley, E., S.J. Jones, and L.W. Gold, eds. Physics and chemistry of ice. Ottawa, Royal Society of Canada, 262-267.
Paren, J.G. and Robin, G. de Q. 1975. Internal reflections in polar ice sheets. J. Glaciol., 14(71), 251-259.

Reynolds, J.M. 1985. Dielectric behaviour of firn and ice from the Antarctic Peninsula, Antarctica. J. Glaciol., 31(109), 253-262.

Robin, G. de Q., S. Evans, and J.T. Bailey. 1969. Interpretation of radio echo sounding in polar ice sheets. Philos. Trans. R. Soc. London, Ser. A, 265(1166), 437505.

Schwander, J., A. Neftel, H. Oeschger, and B. Stauffer. 1983. Measurement of direct current conductivity on ice samples for climatological applications. J. Phys. Chem., 87(21), 4157-4160.

Takei, I. and N. Maeno. 1987. Electric characteristics of point defects in HCl-doped ice. J. Phys. (Paris), 48, Colloq. $\mathrm{Cl}, 121-126$. (Supplément au 3.)

Wolff, E.W. and J.G. Paren. 1984. A two-phase model of electrical conduction in polar ice sheets. J. Geophys. Res., 89(B11), 9433-9438.

Wolff, E.W., R. Mulvaney, and K. Oates. 1988. The location of impurities in Antarctic ice. Ann. Glaciol., 11, 194-197. 